\title{
PREDIKSI BISNIS FOREX MENGGUNAKAN MODEL NEURAL NETWORK BERBASIS ADA BOOST MENGGUNAKAN 2047 DATA
}

\author{
Suyatno \\ Fakultas Sains dan Teknologi, Program Studi Sistem Informasi \\ Universitas Islam Nahdlatul Ulama Jepara \\ Email: yatno.fsaintek@gmail.com \\ Sisno Riyoko \\ Fakultas Sains dan Teknologi, Program Studi Teknik Industri \\ Universitas Islam Nahdlatul Ulama Jepara \\ Email: riyoko.lppm@gmail.com \\ R. Hadapiningradja Kusumodestoni \\ Fakultas Sains dan Teknologi, Program Studi Teknik Informatika \\ Universitas Islam Nahdlatul Ulama Jepara \\ Email: kusumodestoni@gmail.com
}

\begin{abstract}
ABSTRAK
Setelah melakukan penelitian dan percobaan maka didapatkan hasil penelitian pertama yang telah dilakukan dengan menggunakan Algoritma Neural Network Backpropagatioan dengan menggunakan data sebanyak 268 menunjungkan tingkat akurasi error prediksi pada waktu prediksi per 5 menit sebesar 0.758619403 , bila menggunakan data sebanyak 2047 menunjukkan tingkat akurasi error prediksi sebesar 0.500161212 dan hasil penelitian kedua yang telah dilakukan menggunakan Algoritma Optimasi Adaboost pada proses trainning dan ditambah Neural Network Backpropagation pada proses learning menunjukkan tingkat akurasi error prediksi pada waktu prediksi per 5 menit menggunakan data sebanyak 268 sebesar 0.397014925 , bila menggunakan data sebanyak 2047 menunjukkan tingkat akurasi error prediksi sebesar 0.099951148. Tahap awal dalam melakukan penelitian ini sampai dengan pengujian menggunakan perhitungan prediksi nilai akurasi error menggunakan rumus MSE (Mean Sequare Error) dengan menggunakan algoritma optimasi adaboost untuk memberikan jawaban atas permasalahan bahwa nilai akurasi error Algoritma Neural Network Backpropagation perlu direndahkan agar akurasi prediksi meningkat dan tahap kedua dilakukan uji coba menggunakan data yang lebih banyak dibandingan dengan tahap ke satu. Berdasarkan hasil penelitian yang telah dilakukan, dapat disimpulkan bahwa Algoritma Neural Network memiliki akurasi yang lebih rendah bila dibandingkan dengan akurasi menggunakan metode optimasi adaboost pada proses trainning ditambah dengan Neural Network, ini dapat dilihat dengan rendahnya tingkat error MSE menggunakan metode adaboost + neural network dan dapat disimpukan pula bahwa dengan menggunakan jumlah data yang lebih banyak maka dapat menurunkan tingkat akurasi error MSE sehingga berhasil meningkatkan akurasi prediksi dalam bisnis forex trading.
\end{abstract}

Kata kunci: forex, trading, neural network, adaboost, central capital futures.

\section{ABSTRACT}

After conducting research and experiments then showed the first research that has been done using Algorithm Neural Network Backpropagatioan using data from as many as 268 menunjungkan accuracy rate error prediction when the prediction per 5 minutes by 0.758619403 , when using the data as much as 2047 showed levels of accuracy error prediction for 0.500161212 and the results of a second study was done using Algorithm Optimization Adaboost in the process of trainning and coupled Neural Network Backpropagation in the learning process indicates the level of accuracy error prediction when the prediction per 5 minutes uses as much data as 268 by 0.397014925, when using the data as much as 2047 showed levels of accuracy error prediction by 0.099951148.Early stage in conducting this study to test using the calculation value prediction accuracy error using the formula MSE (Mean Sequare Error) using optimization algorithms adaboost to provide answers to the problems that the accuracy error Algorithm Neural Network Backpropagation need to be humbled in order of prediction accuracy increases and the second stage conducted trials using more data compared with phase one. Based on the research that has been done, it can be concluded that the Algorithm Neural Network has lower accuracy than the accuracy of using the optimization method adaboost in the process of trainning coupled with Neural Network, this can be seen with the low level of error MSE method adaboost + neural network and can disimpukan also that by using a more amount of data it can lower the level of accuracy error MSE thus succeeded in improving the accuracy of predictions in forex trading business.

Keywords: forex, trading, neural network, adaboost, central capital futures. 


\section{PENDAHULUAN}

Ada banyak jenis investasi yang dapat kita lakukan untuk menghasilkan keuntungan yaitu ada dalam bentuk aset Riil dan ada yang dalam bentuk aset Finansial. Investasi dalam bentuk aset riil adalah salah satu jenis investasi yang asetnya memiliki wujud misalnya dalam bentuk tanah, emas, rumah, dan logam mulia yang lain. Sedangkan jenis investasi dalam bentul aset finansial adalah jenis aset yang wujudnya tidak terlihat, tetapi tetap memiliki nilai yang tinggi misalnya saham, reksa dana, obligasi, dan forex [1].

Salah satu jenis investasi yang saat ini banyak digemari adalah forex. Forex berasal dari kata "Foreign Exchange" yang artinya adalah pertukaran mata uang asing, atau pertukaran mata uang yang satu dengan mata uang yang lainnya, sedangkan forex trading adalah kegiatan membeli atau menjual mata uang secara terus menerus dan konsisten untuk mendapatkan keuntungan dengan cara memprediksi dengan benar. Forex merupakan pasar keuangan terbesar dan terlikuid di dunia dengan omset harian sekitar 1 triliun US 1 triliun US dolar [2]. Forex berdiri pada tahun 1973 dengan deregulasi nilai tukar mata uang asing di Amerika Serikat dan negara lainnya. Yaitu, pada tahun 1973 terjadi pertukaran rezim pada Mata uang global. Ini didasarkan pada perjanjian Bretton Woods pada tahun 1944 dengan dolar Amerika sebagai dasar untuk semua mata uang dunia yang bebas. Selain Amerika Tidak ada negara lain yang dijamin untuk pertukaran mata uang untuk emas. Akibat adanya kenaikan inflasi maka nilai dolar lebih menjadi bernilai kurang, dan pemegang dolar di seluruh dunia mencari keselamatan emas. Ini menyebabkan banyak negara tidak dapat mempertahankan nilai mata uang mereka di bawah rezim Bretton Woods, dan cadangan emas Amerika Serikat menurun secara signifikan [3]. Pedagang pasar Forex dapat menggunakan banyak cara untuk menganalisis arah pasar forex. Dengan demikian, dengan mempelajari sejarah pergerakan harga di masa lalu maka pergerakan harga di masa depan dapat diprediksi.

Prediksi adalah salah satu kegiatan untuk menebak atau meramalkan masa yang akan datang dengan cara memeriksa data-data di masa lalu. Prediksi dapat terdiri dari hasil estimasi bias dari besarnya masa yang akan datang dengan beberapa variabel, seperti penjualan, atas dasar pengetahuan di masa lalu, sekarang, dan pengalaman. Keputusan dalam memprediksi sangatlah penting, karena setiap kesalahan dalam prediksi akan membuat investor kehilangan uang yang telah mereka investasikan [4]. Untuk itu setiap investor harus dapat memprediksi nilai tukar uang dalam pasar modal, mereka harus memiliki beberapa informasi untuk membuat prediksi di masa yang akan datang. Informasi yang baik dan jelas akan mempermudah dalam melalukan prediksi dan prediksi yang baik yaitu prediksi dengan tingkat akurasi yang tinggi.

Diperlukan metode yang tepat untuk melakukan prediksi secara akurat. Ada banyak algoritma yang dapat digunakan untuk memprediksi salah satunya adalah Neural network dan ada banyak algoritma optimasi yang dapat digunakan untuk mengurangi akurasi error dalam memprediksi dan salah satu algoritma tersebut adalah Adaboost. Adaboost adalah salah satu algoritma optimasi yang dapat mengurangi akurasi error dalam prediksi.

Neural Network atau yang biasa disebut juga Artificial Neural Network adalah salah satu cabang dari ilmu kecerdasan buatan (artificial intelligence) yang merupakan salah satu sistem pemrosesan, perencanaan dan perancangan informasi yang didesain dengan menirukan cara kerja otak manusia untuk menyelesaikan suatu masalah. Alexander dan Morton dalam Suyanto mendefinisikan bahwa Neural Network sebagai prosesor yang tersebar secara paralel yang sangat besar dengan memiliki kecendeungan untuk menyimpan pengetahuan yang bersifat pengalaman atau data-data yang telah terjadi di masa lalu dan membuatnya untuk siap digunakan. Neural Network dibentuk sebagai generalisasi model matematika dari jaringan syaraf biologi dengan asumsi bahwa pemrosesan, perencanaan, dan perancangan informasi terjadi pada banyak elemen sederhana (neuron); sinyal dikirimkan diantara neuron-neron melalui penghubung-penghubung; penghubung antar neuron memiliki bobot yang akan memperkuat atau memperlemah sinyal; dan untuk menentukan output setiap neuron menggunakan fungsi aktivasi yang dikenakan pada jumlahan input yang diterima, besarnya output ini selanjutnya dibandingkan dengan suatu batas ambang. Dengan demikian ANN ditentukan oleh tiga hal, yaitu: pola hubungan antar neuron (disebut arsitektur jaringan), metode untuk menentukan bobot penghubung (disebut metode training/ learning/ algoritma), dan fungsi aktivasi. ANN telah banyak diaplikasikan dan sangat sukses digunakan untuk memecahkan berbagai masalah dalam berbagai disiplin ilmu seperti bidang komputer, teknik, perdagangan, financial dan lain-lain [10].

Model Adaboost atau yang biasa disebut juga boosting adalah salah satu model yang dapat meningkatkan ketelitian dalam proses klasifikasi dan prediksi dengan cara membangkitkan kombinasi dari suatu model, tetapi hasil klasifikasi atau prediksi yang dipilih adalah model yang memiliki nilai bobot paling besar. Jadi, setiap model yang dibangkitkan memiliki atribut berupa nilai bobot. Salah satu algoritma boosting yang populer adalah Adaboost. Pada algoritma Adaboost ini, pertama-tama nilai bobot untuk setiap tuple pada himpunan D diinisialisasi sebesar 1/d (d=jumlah anggota himpunan D). Setelah suatu model Mi dibangkitkan, kemudian dihitung tingkat kesalahannya (error rate), dengan cara menjumlahkan nilai bobot dari setiap tuple yang misclassified (salah klasifikasi) pada Mi [11]. 


\section{METODOLOGI PENELITIAN}

\subsection{Teknik Pengumpulan Data}

Kajian terhadap prediksi forex ini memberikan peluang berkembangnya pemahaman yang lebih mendalam tentang pengenalan cara memprediksi secara akurat. Oleh karena itu, pengumpulan data tentang prediksi forex ini lebih mengutamakan penggunaan teknik observasi guna mengumpulkan data prediksi pada waktu waktu sebelumnya. Adapun detail kerja secara teknik masing-masing dapat dijelaskan sebagai berikut.

a. Instrumen Penelitian

Dalam mengumpulkan data, peneliti sebagai instrumen utama penelitian ditunjang dengan penggunakan alat-alat bantu yaitu wawancara alat bantu ini digunakan sebagai panduan dalam melakukan wawancara dengan informan agar diperoleh data yang diperlukan dalam upaya menemukan jawaban atas rumusan masalah penelitian dan media penyimpanan Flash Disk. Media penyimpanan ini digunakan untuk memperoleh data database hasil prediksi di waktu waktu terdahulu.

b. Observasi

Peneliti melakukan pengamatan langsung di lapangan, yaitu di PT. Central Capital Future cabang Surabaya dengan alamat Graha SA Office Building Ground Floor, Jl. Raya Gubeng 1921, Surabaya 60281 Jawa Timur. Dalam penelitian ini, hasil pengamatan diposisikan sebagai data primer. Kegunaan observasi ini adalah Untuk mendapatkan pengalaman langsung dalam mengamati jalannya bisnis forex trading sebagai alat untuk untuk mengecek ulang kebenaran informasi yang diperoleh bahwa kerugian yang dialami oleh pebisnis forex dapat menimbulkan stres pada pebisnis forex dan untuk memperoleh pengalaman langsung dari sebuah pengamatan terhadap jalannya proses trading forex.

\subsection{Metode Training Menggunakan Ada Boost}

Adaboost pada penelitian ini digunakan pada proses training dari hasil pengumpulan data. Dalam proses training data forex (nilai tukar mata uang asing) kemudian akan diproses terlebih dahulu berfungsi untuk mengubah nilai nominal menjadi numerik, karena adaboost tidak dapat membaca nilai nominal. Dari hasil data numerik tersebut kemudian adaboost digunakan untuk mentraining data prediksi.

\subsection{Metode Learning Menggunakan Neural Network}

Penelitian ini menggunakan Neural Network dalam proses learning, sebelum proses learning data forex (nilai tukar mata uang asing) akan diproses terlebih dahulu untuk mengubah nilai nominal menjadi numerik.

\subsection{Metode Testing}

Pada tahap metode ini data hasil pengolahan antara training menggunakan adaboost dan learning menggunakan neural network di testing guna mengukur berapa akurasi trend dari prediksi.

\subsection{Metode Evaluasi dan Validasi}

Terdapat banyak algotrima yang dapat dipakai untuk memprediksi nilai tukar mata uang asing namun belum diketahui apakah model neural network berbasis ada boost memiliki kinerja lebih akurat dan tingkat error yang rendah. Sehingga perlu diuji untuk mengetahuinya. Algoritma ini akan di implementasikan dengan menggunakan Rapid Miner 5.1.001x32. Metode yang diusulkan adalah metode analisa tingkat akurasi dari algoritma backpropagation berbasis ada boost untuk memprediksi bisnis forex.

\section{HASIL DAN PEMBAHASAN}

Dari hasil penerapan menggunakan algoritma optimasi Adaboost untuk meningkatkan akurasi prediksi bisnis forex dengan menggunakan data nilai tukar mata uang yang di dapat dari PT. Central Capital Future Cabang Surabaya dengan menggunakan Rapid Miner 5.1. maka didapat hasil bahwa Algoritma Neural Network memiliki akurasi yang lebih rendah bila dibandingkan dengan akurasi menggunakan metode optimasi adaboost pada proses trainning ditambah dengan Neural Network, ini dapat dilihat dengan rendahnya tingkat error MSE menggunakan metode adaboost+neuralnetwork dan 
dapat disimpukan pula bahwa dengan menggunakan jumlah data yang lebih banyak maka dapat menurunkan tingkat akurasi error MSE sehingga berhasil meningkatkan akurasi prediksi dalam bisnis forex trading.

a. Grafik Tren Akurasi Prediksi Per 5 Menit menggunakan 268 Data

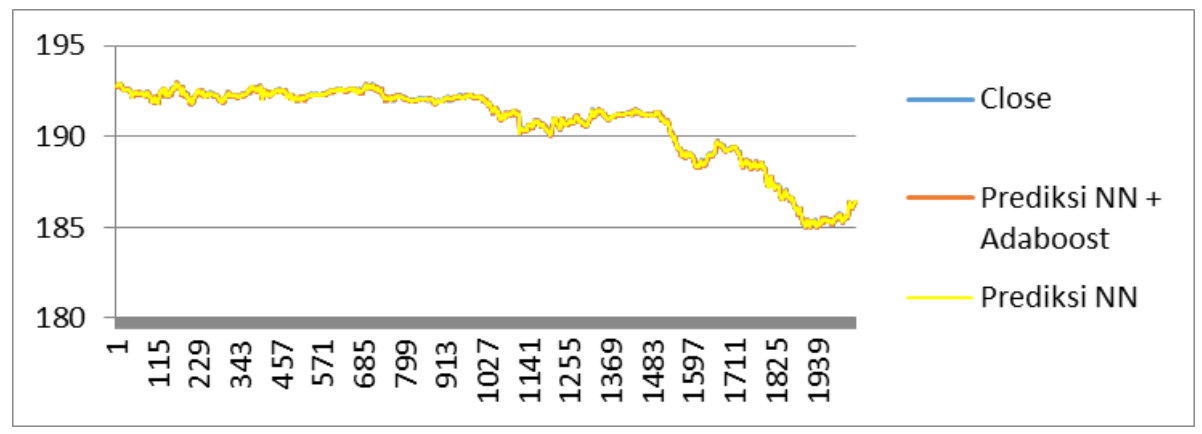

\section{Gambar 1. Grafik Prediksi Akurasi Nilai Tukar Mata Uang Pada Bisnis Forex Per 5 Menit Menggunakan 268 Data}

Dari gambar 1 diatas menunjukkan grafik akurasi hasil prediksi nilai tukar mata uang pada bisnis forex per 5 menit menggunakan 268 data. Contoh pada grafik saat penutupan tanggal 9 Juli 2015 pukul 05:35 nilai tukar mata uang sebesar 186.34 yang diprediksi oleh algoritma neural network sebesar 186.54, kemudian pada menit yang kedua nilai tukar mata uang ditutup dengan nilai sebesar 186.36 yang diprediksi oleh algoritma neural network sebesar 186.57, dari hasil prediksi tersebut diatas disimpulkan bahwa nilai akurasi error prediksi pada nilai tukar mata uang per 5 menit menggunakan algoritma neural networks sebesar 0.758619403. sedangkan grafik saat penutupan tanggal 9 Juli 2015 pukul 05:35 nilai tukar mata uang sebesar 186.34 yang diprediksi oleh algoritma neural network + Adaboost sebesar 186.36, kemudian pada menit yang kedua nilai tukar mata uang ditutup dengan nilai sebesar 186.36 yang diprediksi oleh algoritma neural network + Adaboost sebesar 186.38, dari hasil prediksi tersebut diatas disimpulkan bahwa nilai akurasi error prediksi pada nilai tukar mata uang per 5 menit menggunakan algoritma neural networks + adaboost sebesar 0.397014925 .

b. Grafik Tren Akurasi Prediksi Per 5 Menit menggunakan 2047 Data

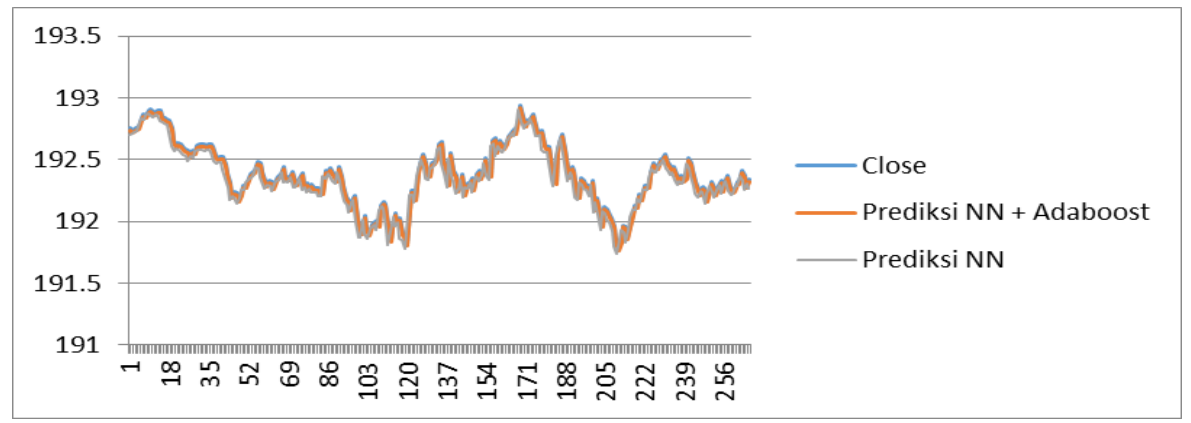

\section{Gambar 2. Grafik Prediksi Akurasi Nilai Tukar Mata Uang Pada Bisnis Forex Per 5 Menit Menggunakan 2047 Data}

Dari gambar 2. diatas menunjukkan grafik akurasi hasil prediksi nilai tukar mata uang pada bisnis forex per 5 menit menggunakan 2047 data. Contoh pada grafik saat penutupan tanggal 9 Juli 2015 pukul 05:35 nilai tukar mata uang sebesar 186.34 yang diprediksi oleh algoritma neural network sebesar 186.41, kemudian pada menit yang kedua nilai tukar mata uang ditutup dengan nilai sebesar 186.36 yang diprediksi oleh algoritma neural network sebesar 186.39, dari hasil prediksi tersebut diatas disimpulkan bahwa nilai akurasi error prediksi pada nilai tukar mata uang per 5 menit menggunakan algoritma neural networks sebesar 0.500161212. sedangkan grafik saat penutupan tanggal 9 Juli 2015 pukul 05:35 nilai tukar mata uang sebesar 186.34 yang diprediksi oleh algoritma neural network + Adaboost sebesar 186.35, kemudian pada menit yang kedua nilai tukar mata uang ditutup dengan nilai sebesar 186.36 yang diprediksi oleh algoritma neural network + Adaboost sebesar 186.37, dari hasil prediksi tersebut diatas disimpulkan bahwa nilai akurasi error prediksi pada nilai tukar mata uang per 5 menit menggunakan algoritma neural networks + adaboost sebesar 0.099951148 . 
Grafik pengukuran keandalan prediksi dengan menggunakan MSE (Mean Sequare Error) Nilai akurasi prediksi dikatakan tinggi apabila nilai MSEnya rendah maka untuk mengukur keandalan prediksi dalam penelitian ini menggunakan MSE (Mean Sequare Error).

Dari hasil percobaan prediksi yang telah dilakukan maka didapat:

MSE $=\sum \frac{\left|D_{\mathrm{t}}-F_{\mathrm{t}}\right|^{2}}{n}$

Keterangan :

$\begin{array}{lll}\text { MSE } & : \text { Mean Sequare Error } \\ \mathrm{D}_{\mathrm{t}} & : \text { Close } \\ \mathrm{F}_{\mathrm{t}} & : & \text { Prediksi } \\ \mathrm{N} & : & \text { Total jumlah periode }\end{array}$

Tabel 1. Akurasi error prediksi nilai tukar mata uang Great Britain Poundsterling (GBP) terhadap Japanese Yen

\begin{tabular}{llcc}
\hline No. & Waktu Prediksi & MSE Neural Network & MSE Adaboost + NN \\
\hline 1. & $\begin{array}{l}\text { Per 5 Menit } \\
\text { dengan 268 data }\end{array}$ & 0.758619403 & 0.397014925 \\
2. & $\begin{array}{l}\text { Per 5 Menit } \\
\text { dengan 2047 data }\end{array}$ & 0.500161212 & 0.099951148 \\
\hline
\end{tabular}

Tabel 1 adalah menjelaskan tentang akurasi error prediksi nilai tukar mata uang Great Britain Poundsterling $(G B P)$ terhadap Japanese Yen, yang mana terlihat hasil waktu prediksi 5 menit dengan menggunakan 268 data di dapat nilai error MSE menggunakan metode Neural Network sebesar 0.758619403 dan nilai error MSE menggunakan metode Adaboost $+N N$ sebesar 0.397014925 dan hasil waktu prediksi 5 menit dengan menggunakan 2047 data di peroleh nilai error MSE menggunakan metode Neural Network sebesar 0.500161212 dan nilai error MSE menggunakan metode Adaboost $+N N$ sebesar 0.099951148

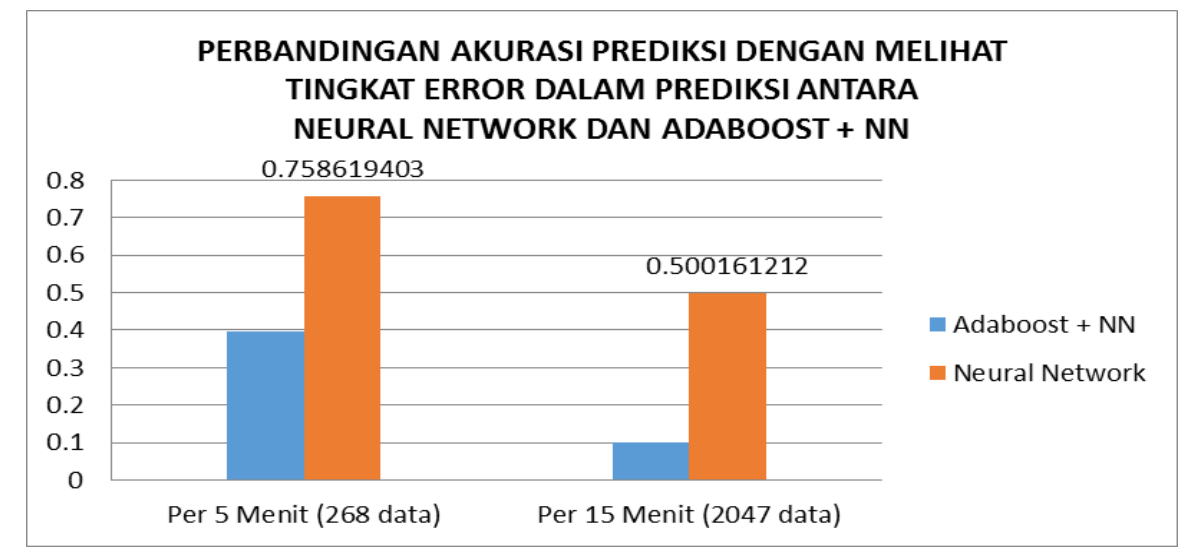

Gambar 3. Keandalan Prediksi Menggunakan MSE

Dari Tabel 1 dan Gambar 3 tentang Grafik Keandalan prediksi menggunakan MSE di atas didapat nilai kesalahan error prediksi per 5 menit menggunakan data sebanyak 268 dan dengan menggunakan metode Neural Network sebesar 0.758619403 sedangkan nilai kesalahan error adaboost lebih rendah yaitu sebesar 0.397014925, nilai kesalahan error prediksi per 5 menit menggunakan data sebanyak 2047 dan dengan menggunakan metode Neural Network sebesar 0.500161212 sedangkan nilai kesalahan error adaboost lebih rendah yaitu sebesar 0.099951148. Sehingga dapat disimpulkan bahwa Nilai MSE Adaboost $+N N$ dalam memprediksi lebih kecil dibandingkan Neural Network maka nilai prediksi menggunakan Adaboost lebih akurat dibandingkan dengan neural network dan Nilai MSE menggunakan data yang sedikit menghasilkan nilai MSE yang besar sedangkan bila menggunakan data yang lebih banyak menghasilkan nilai MSE yang lebih kecil.

\section{KESIMPULAN}

Setelah melakukan penelitian dan percobaan maka didapatkan hasil penelitian pertama yang telah dilakukan dengan menggunakan Algoritma Neural Network Backpropagatioan dengan menggunakan 
data sebanyak 268 menunjungkan tingkat akurasi error prediksi pada waktu prediksi per 5 menit sebesar 0.758619403 , bila menggunakan data sebanyak 2047 menunjukkan tingkat akurasi error prediksi sebesar 0.500161212 dan hasil penelitian kedua yang telah dilakukan menggunakan Algoritma Optimasi Adaboost pada proses trainning dan ditambah Neural Network Backpropagation pada proses learning menunjukkan tingkat akurasi error prediksi pada waktu prediksi per 5 menit menggunakan data sebanyak 268 sebesar 0.397014925 , bila menggunakan data sebanyak 2047 menunjukkan tingkat akurasi error prediksi sebesar 0.099951148 .

Tahap awal dalam melakukan penelitian ini sampai dengan pengujian menggunakan perhitungan prediksi nilai akurasi error menggunakan rumus MSE (Mean Sequare Error) dengan menggunakan algoritma optimasi adaboost untuk memberikan jawaban atas permasalahan bahwa nilai akurasi error Algoritma Neural Network Backpropagation perlu direndahkan agar akurasi prediksi meningkat dan tahap kedua dilakukan uji coba menggunakan data yang lebih banyak dibandingan dengan tahap ke satu.

Berdasarkan hasil penelitian yang telah dilakukan, dapat disimpulkan bahwa Algoritma Neural Network memiliki akurasi yang lebih rendah bila dibandingkan dengan akurasi menggunakan metode optimasi adaboost pada proses trainning ditambah dengan Neural Network, ini dapat dilihat dengan rendahnya tingkat error MSE menggunakan metode adaboost + neural network dan dapat disimpukan pula bahwa dengan menggunakan jumlah data yang lebih banyak maka dapat menurunkan tingkat akurasi error MSE sehingga berhasil meningkatkan akurasi prediksi dalam bisnis forex trading.

\section{DAFTAR PUSTAKA}

[1] Abraham and M.U. Chowdhury, 2010, "Australian Forex Market Analysis Using Connectionist Models," Training, pp. 1-13.

[2] A.A. Philip, 2011, "Artificial Neural Network Model for Forecasting Foreign Exchange Rate," Information Technology Journal, vol. 1, pp. 110-118.

[3] M.H. Eng, Y. Li, Q. Wang, and T.H. Lee, 2008, "Forecast Forex With ANN Using Fundamental Data," Architecture, pp. 1-4.

[4] A.S. From and A. Neural, 2007, "IIGSS Academic Publisher Are Foreign Exchange Rates Predictable ? A Survey From Artificial Neural Networks Perspective *," Exchange Organizational Behavior Teaching Journal, vol. 8, pp. 207-227.

[5] J. Kamruzzaman and R.A. Sarker, 2009, "Comparing ANN Based Models with ARIMA for Prediction of Forex Rates," vol. 22, pp. 2-11.

[6] K.K. Lai, L. Yu, and S. Wang, 2008, "A Neural Network and Web-Based Decision Support System for Forex Forecasting and Trading," Framework, pp. 243-253.

[7] G. Hu, F. Zhu, and Y. Zhang, 2009, "Study of Integrating AdaBoost and Weight Support Vector Regression Model,"

[8] M. Ibrahim and B.R. Lan, 2007, "University technology mara foreign exchange market prediction using standard backpropagation neural network"

[9] Gordon and H.D. Jr, 2009, "Forecasting Forex Rates,".

[10] Physics, 2008, "Using Recurrent Neural Networks To Forecasting of Forex," Time.

[11] Dunis, M. Williams, and Mark, 2009, "Modelling and trading the eur/usd exchange rate: do neural network models perform better," Derivatives Use, Trading \& Regulation, vol. vol, pp. 8no3pp211239.

[12] P. Sutheebanjard, 2010, "Stock Exchange of Thailand Index prediction using Back Propagation Neural Networks," Exchange Organizational Behavior Teaching Journal, pp. 2-5.

[13] Ahmad, 2009, "SVM Based Models for Predicting Foreign Currency Exchange Rates," Journal of Management, pp. 0-3.

[14] C. Services, 2008, "Forecasting Daily Foreign Exchange Rates Using Genetically Optimized Neural," Journal of Forecasting, vol. 511, pp. 501-511.

[15] X. Wu, V. Kumar, J.R. Quinlan, J. Ghosh, Q. Yang, H. Motoda, G.J. Mclachlan, A. Ng, B. Liu, P.S. Yu, Z.Z. Michael, S. David, and J.H, 2008, "Top 10 algorithms in data mining," Knowledge and Information Systems, pp. 1-37.

[16] X. Zhang and F. Ren, 2008, "Improving Svm Learning Accuracy with Adaboost," Learning, pp. 221-225.

[17] C. Dunis, M. Williams, and Mark, 2009, "Modelling and trading the eur/usd exchange rate: do neural network models perform better," Derivatives Use, Trading \& Regulation, vol. vol, pp. 8no3pp211-239.

[18] X. Zhang and F. Ren, 2008, "Improving Svm Learning Accuracy with Adaboost," Learning, pp. 221-225. 